$\mathbb{T}$ periodica polytechnica

\author{
Civil Engineering \\ $58 / 2(2014) 121,129$ \\ doi: 10.3311/PPci.2158 \\ http://periodicapolytechnica.org/ci \\ Creative Commons Attribution (1) \\ RESEARCH ARTICLE
}

\section{Quality measuring numbers of milled edges of granite surfaces}

Miklós Gálos / István Gábor Gyurika

Received 2013-06-19, revised 2014-04-03, accepted 2014-04-16

\begin{abstract}
Automated machining of various stones made products such as tiles, statues, machine tool and measuring machine tables are expanding and evolving. In case of stone milling processes arises a problem which is that right now there is no objective and generally usable measuring system which would define the characteristics of milled edge chipping. In this paper a qualifying model is introduced that could define the maximal chipping depth and average chipping measure of milled edges of granite products. While the second part of this paper will depict the process of investigation. Volume reduction of the product that happened because of chipped substances on the edges during milling can be defined with the help of this process. During the investigation we used NC controlled stone machining centers, laser scanners and rapid prototyping softwares. During the research we have defined the shape that could replace the chipped parts with great precisions.
\end{abstract}

\section{Keywords}

granite $\cdot$ milling $\cdot$ quality $\cdot$ edge chipping $\cdot$ automatization

\section{Introduction}

Various stone types are used to make tiles in the building industry. Most common stones in building and decorative stone industry are limestone, marble and granite. Granite is also used in production engineering where mostly the tables of measuring machines and great precision machine tools are made. To reduce production costs automated machine tools are used for stone machining whether it is a machine bed, statue, tile or kitchen element it does not matter. Because of this NC controlled machine tools namely numerical controlled cutting machines, sawing machines, sanding machines and the newly developed stone machining centers has come into view even at stone machining processes during the previous decade (Fig. 1)

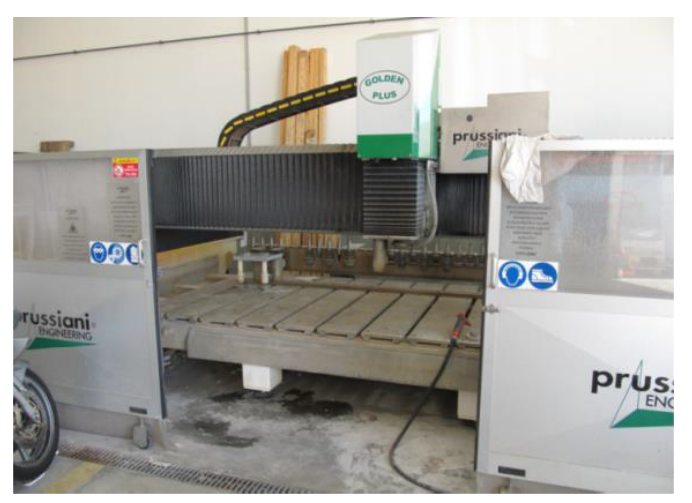

Fig. 1. CNC stone-milling machine

During milling of stones with NC machining center - mostly during the production of faces and spigots - a general problem arises that is the chipping of edges of various degrees. This chipping process is parallel to the burr appearing during stone machining. While this burr can be removed with follow-up machining the chipping appearing in case of stone milling is a material destruction that cannot be repaired since in this case it was not material conversation but material removal.

A requirement concerning the edge chipping of various stone types appears in numerous cases to satisfy costumers' needs. However presently there is no objective measuring number or system that would help the costumer clearly define the allowed chipping measure of the given product. Goal of the research 
depicted in this paper is to make an objective qualifying system that is proportional to the real chipping value and is suitable for the industry.

\section{Researches concerning stone surface qualification}

Concerning the qualification of stone surfaces a great number of researches and developed measuring algorithms can be found in international scientific literature. Most of these researches is about cutting, sawing and grinding of stones. However these researches are just indirectly deals with the qualification of edges.

Kertész et al [1] have written an overall paper about the petrographical problems of building and decorating stones. In their researches they have focused mainly on stone types used in the renaissance era. They have analyzed the characteristics and mistakes of stones used constructions of the time in detail.

Bagi et al [2] have examined the parameters causing significant dispersion during measuring uniaxial compression strength in case of natural stones. Analyzing data of the executed researches they have stated that differences between the results of each experiment play a significant role in geometrical probability of microstructure of rocks and properties of rock fabric.

Ribeiro et al [3] have examined the effects caused by surface roughness of granite to machinability and applicable technological parameters. Main goal of these researches was to explore the connection between surface quality of tiles and dynamic coefficient of friction. During the research five granite tiles were cut then surface quality was measured in various technological parameters with the help of a portable surface roughness tester. From outcome of researches they have concluded that mineral structure and micro-structural surface are greatly responsible for surface roughness of tiles.

Xie [4] has examined precision machining of granites depending on microhardness and microbrittleness parameters. During the research machinings were executed with an NC controlled stone cutting machine using several technological parameters. Analyzing the diagrams found in this publication the researcher concluded that thanks to growing microhardness and decreasing average dispersion, the surface roughness reduces while machining force is growing. So to reach a better surface quality bigger energy consumption is needed.

Huang et al [5] have examined interactions between diamond disk and surface of stone in case of three granite types. During machining they have measured the force influencing main spindle and changes of temperature on the surface of disk-granite. Outcome of researches has shown that the highest grown in temperature is not sufficient to influence shininess of established granite surface.

Huang [6] has examined the connection between size of diamond grains inside the tool and possible surface roughness established by this tool in case of grinding processes For measuring purposes scanning electronic microscope that is able to define surface morphology, a digital shininess measuring machine and a portable surface roughness tester were used. Researches have shown that shininess can be linked to adjustable surface roughness.

Polini et al [7] have examined changes in machining force depending on cutting depth and machining speed in case of cutting and milling. For the researches they used a CNC machining centre and a diamond mill with a diameter $20 \mathrm{~mm}$. The workpiece material was Coreno Perlato Royal marble. Three feed speed values and 14 cutting depth values were taken into account. Researches done by diamond milling tool has shown that machining force greatly depends on feedrate and cutting depth.

Among international sources there are also several researches related to the edge chippings [8] examined edge chippings in the case of oxide and nonoxide ceramics near the applications of different loads. During the examination process as a first step they chose a point near by the edge of the workpiece by naked eye or by magnifying glass, then they dropped a Rockwell-intender on the point. The effect of this was the formation of the edge chipping. After this they measured the distance between the chipping and the edge with the help of an Olympus BX51 measuring microscope. As a result of the researches it can be stated that the edge chipping examination and the established evaluating algorithm those were introduced in the article are absolutely appropriate for implementing practical examinations. The established edge chipping process and the measuring and evaluating algorithm related to it make it possible to accurately determine the fracture toughness of ceramics.

Near ceramics a number of researches were also implemented in connection with the edge chippings of glass products. Mohajerani et al [9, 10] examined the edge chipping process of borosilicate glass materials as the effect of low-velocity impact through a number of researches. They examined the edge chippings of the mentioned material on an experimental way, where the edge chippings were caused by steel and ceramic blocks those were falling freely with a low velocity. They measured the maximum impact force with the help of a force sensor and they examined the relationship between the impact force and the rate of edge chipping caused by it. During the experiments they examined a number of edge chipping types from the mildest split to the coarsest chipping. As a result they stated that the initial stages of the fracture processes developed clearly similarly in the cases of their own experiments and the quasi-static penetration. However in the case of impact-based experiments the forces needed for the formations of edge chippings were much lower than the ones of quasi-static penetrations.

The edge chippings of natural stones were researched only by a few in the last years. Direct results were publicized by Bao et al [11]. During their examinations the researchers established a new model to estimate the forces those were necessary for the formation of edge chippings near the usage of a tool with concentrated load. Their aim was to prove that the chips those were formed during machining had similar geometries independent from their materials. Their further aim was to determine the relationship between the maximum force which appeared at the 
moment before the beginning of fracture and the distance of the load from the edge. They implemented a number of experiments on sandstones. The research showed that the former articles in this field estimated wrong stress conditions and their equations leaded to the false calculation of cutting force. The model developed by Bao et al is based on the analysis of the loading force and the energy distribution, using the knowledge on fracture mechanics and the results of cutting tests implemented on different stones. According to the examinations the researchers drew the conclusion that there was an obvious relationship between the distance of the load from the edge and the maximum force, and on the basis of this they established an estimation system on the measurement results. They approximated the geometry of the edge chipping with a quarter ellipsoid-shaped model.

\section{Qualifying needs of milled edges of granite products}

When milling spigots and faces of various rock types, various surfaces are made using a segmented milling tool on NC machine tools (Fig. 2). Goal of the process during milling is to define the final product size. For this reason the tool can remove more than one millimeter thick material during one cutting road. After the milling process a grinding operation can be used to reach final surface quality. If the rock does not need particularly low surface roughness, then milling is used as a final machining process.

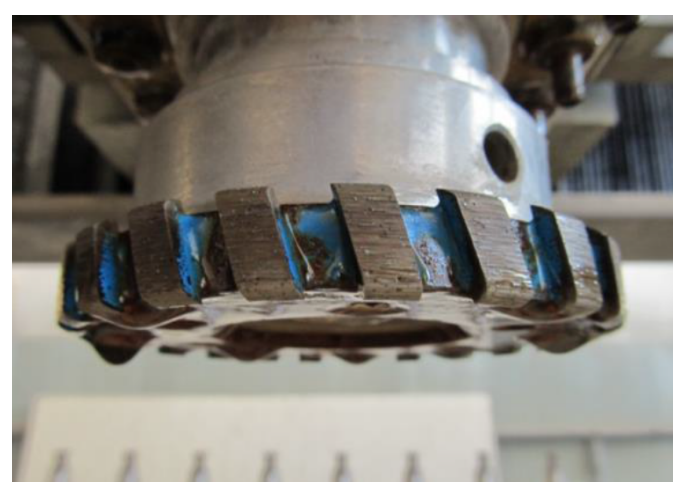

Fig. 2. Stone-milling tool

When milling granite products more problems arise concerning edge chipping. First is a satisfying costumers' need. Customers can complain if opinion of costumer is that there is unexpected measure of chipping on edges of the final stone-made product. If the costumer thinks chipping is out of the acceptable limit than he can decide not to pay production costs of the product. However this acceptable limit is just a subjective domain that is completely in the hand of costumers and cannot be defined with a measuring number or formula. As a result of this a manufacturer can view a stone-made product surely salable in other words perfectly suitable for costumers needs only when the costumer has inspected it and deemed chipping suitable. Second problem arises when, after production of a face or island, rounding of edges stays a remaining process. The main objective function besides geometry is to achieve zero chipping originated from milling on rounded surface. In this case - if costumer requirements allow flexible alteration of rounding limits it is necessity to know the degree of chipping on the rock, during manufacturing plain surface. However in this instance average rate does not, but maximal edge chipping depth needs to be defined. If that is known we can also define extent of rounding.

\section{Measuring numbers developed during researches}

After defining costumers' needs in case of edges of milled surfaces in granite products, basic theories defining objective measuring numbers of edge quality were developed. Befitting costumer requirements this qualification system consists of the following two elements:

- The "average edge chipping rate", which has defined the average magnitude of edge chipping for a given edge.

- Other measuring number is the "maximal edge chipping depth" which helps manufacturers

To define rounding characteristics it is advisable to analyze how the chipped edge of a stone product is created. Common characteristic of stones is their heterogeneous grain structure. Due to this heterogeneous grain structure, various rock-forming minerals are randomly found in length of workpiece edges. Each mineral has its own binding and strength attribution so various extent of impact makes them break out of the surface of workpiece. Chipping in various minerals also happens in different extents. Some minerals break out node like so only a thin or thick "shell" is left in the material. However there are also minerals breaking out plate like causing less material waste. However extent of chipping only partially depends on grain structure. There are other factors significantly effecting average chipping rate such as the way of machining (up-cutting, down-cutting), applied toolpath, size of diamond grains inside the segment of tool and programmed technological parameters.

During developing the measuring number we have took it into consideration that almost $100 \%$ of manufactured products in field of automated stone machining - it is true for tiles, measuring machine beds, tabletops and kitchen tiles - are made up of edges that their bounding planes are parallel.

\subsection{Defining average edge chipping rate}

So a measuring number is needed that can be used as a base when, defining average chipping rate. Fig. 3 depicts a theoretical sketch of chipped edge of a stone product machined plain. Along the edge extent of chipping is different and the distance between them is different. Volumes of chipping along the edge are on the figurine from $V_{1}$ to $V_{7}$

Base of measuring number is the volume reduction on edges of workpiece as a result of chipping generated during machining. In case of the edge examined in fig. 3. context of whole volume reduction is as follows:

$$
\sum_{i=1}^{n} V_{i}=V_{1}+V_{2}+V_{3}+. .+V_{n}
$$


It can be seen that if we take the theoretical, ideal (without chipping) volume and deduct it from the real volume (after machining) of the workpiece than, we will get the volume reduction of machined edge of workpiece. However this is a value that cannot be generally correlated to a workpiece that has different edge length from the original. So we need a dimensionless measuring number, which can help us generalize the average edge chipping rate.

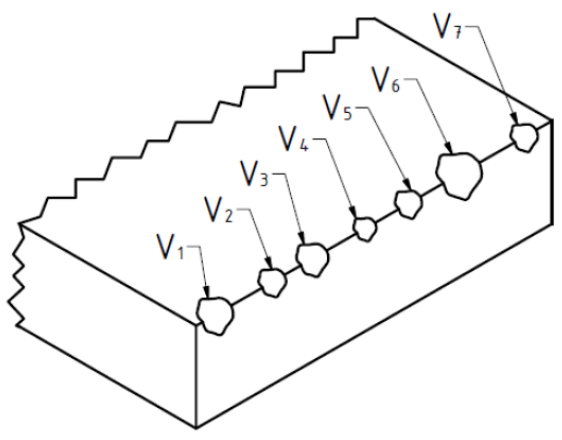

Fig. 3. Theoretical sketch of chipped edge of a stone product

For dimensionless measuring number - which is sovereign of examined edge length - proportionality has to be made that will make a relation between the chipped edged piece and the whole piece. To make a measuring number that can compare average edge chipping rate of different sized pieces, we will need a piece representing the whole volume. Using this is proportionally, the measuring number will become independent of piece size. The piece representing whole volume has been defined as a quarter cylinder (assuming, that the two milled surfaces are orthogonal). This can be seen on fig. 4. The quarter cylinder as the piece representing whole volume its volume is the following:

$$
V_{0}=\frac{r_{h}^{2} \cdot \pi}{4} \cdot L
$$

Where:

- $r_{h}$ is the hypothetical radius of the quarter cylinder [mm]

- $L$ is the length of the investigated edge [mm]

Using this quarter cylinder in the measuring number we can make our edge chipping measuring number from original size of stone product. It is important to make our measuring number independent from the examined edge length since, comparing examinations can only be done between chipped edges of various products.

It is important to define the radius of quarter cylinder representing whole volume. Only factor defining radius is that in which domain we want to use our measuring number. If we take a relatively big radius number thanks to the specificity of algorithm in most cases we get a lower numerical value as solution. In reversed case, if we take " $\mathrm{r}_{h}$ " radius too low, in most cases we get relatively high average edge chipping rate. Taking the simplicity of calculation as a base, we have taken radius of quarter

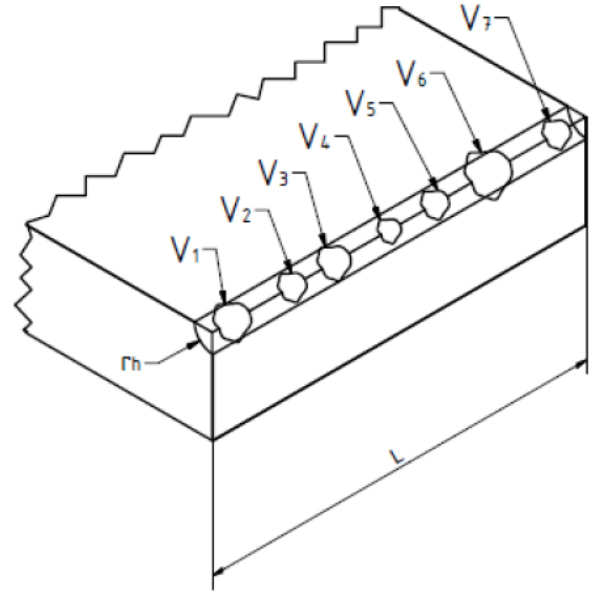

Fig. 4. Adaptation of the quarter cylinder

cylinder as $1 \mathrm{~mm}$. With this $1 \mathrm{~mm}$ radius our quarter cylinder will almost always have bigger value than the sum of chipped volume in the experiments. However it is not likely to have so big value that with its usage a hardly manageable, consequently low average edge cutting rate will we get. This conclusion can be drawn after evaluating the machining experiments found in chapter 5 .

Using a quarter cylinder with $1 \mathrm{~mm}$ radius the volume of the piece representing whole volume is as follows (the measure of Vo is $\mathrm{mm}^{3}$ ):

$$
V_{0}=\frac{r_{h}^{2} \cdot \pi}{4} \cdot L=\frac{1^{2} \cdot \pi}{4} \cdot L=\frac{1}{4} \cdot \pi \cdot L
$$

Average edge chipping rate $\left(\mathrm{M}_{a v g}\right)$ is defined by dimensionless measuring number can be defined as the ratio of chipped volume and volume of the piece representing whole volume:

$$
M_{\text {avg }}=\left(\frac{\sum_{i=1}^{n} V_{i}}{V_{0}}\right)=4 \cdot\left(\frac{\sum_{i=1}^{n} V_{i}}{\pi \cdot L}\right)
$$

Whole volume reduction of examined edge can be get in more way depending on what kind of tools and equipment is available. We can get the sought value using the method described in chapter 5 .

\subsection{Maximal edge chipping depth}

Edge chipping in case of stone machining raises another problem. This problem is planning of the rounding operation in case of work pieces with rounded edge geometry. Rounding (or chamfer) is not only needed for geometrical reasons but in many cases - for example tabletops, plates of kitchen furniture for beautician reasons too. In case of stone products that include rounded edges we have to know the average chipping rate and the maximal edge chipping depth generated by the milling process. With the help of the maximal edge chipping depth the rate 
of round can be defined. The rounding has to be so high - naturally taking into consideration the geometrical viewpoints of the costumers' needs - what causes the chippings generated another time fully disappears. There is no measuring number now that could clearly define the maximal rounding radius that has to be used during rounding with shaped tool to make the chipping, originated from the milling process of finished product edges, completely disappear. Maximal chipping depth is an important element of satisfying costumers' needs. Numerous costumers not only examines average chipping rate of edges of stone products, but also the maximal chipping in several cases. Even if the value of average chipping is under a specified limit, we can find a value of chipping on the machined edge that cannot be viewed suitable ergonomically (for example edges of tabletops) or assembling (in case of products including more stone parts or elements placed on the granite table of coordinate measuring machine). It is recommended to measure the maximal chipping depth also on products that have unrounded edges, but the limit of maximal chipping arises as a need of the costumer.

The measuring number defining maximal chipping depth is an important element of the theoretical measuring model that defines edge chipping characteristics of stone pieces. Defining maximal edge chipping depth is relatively easy however in radical situations we can easily make mistakes. Base of possible mistakes is the inhomogeneous grain structure of stone materials. Because of the inhomogeneous grain structure a case can arise where on the largest part of machined and examined edge the chipping depth stays inside a specific limit however the tearing out of a nodular, board located mineral group generates a chipping depth that is significantly different from the other parts of the edge. Because of this it is definitely important to have a previous inspecting process during defining of maximal chipping depth if we are not measuring the whole edge during the examination.

The maximal chipping value can be defined with a depth value that is defined by the maximal chipping depths found on the two surfaces of the edge. Theoretical base of the examination is depicted on fig. 5

Maximal edge chipping depth is signed by "Mmax" hereinafter. Mmax is maximal material chipping depth compared to the edge in case of edge chipping taken into consideration during the machining and measuring processes.

Choosing of maximal chipping depth:

$$
M_{\max }=\max \left(d_{1 A}, d_{2 A}, d_{3 A}, \ldots, d_{n A}, d_{1 B}, d_{2 B}, d_{3 B}, \ldots, d_{n B}\right)
$$

Defining measuring number of maximal edge chipping value is suitable for defining the minimally needed rounding radius. Using this radius we can make a rounded edge range using shaped milling tool where no edge chipping is left from the milling process. Naturally chipping can also occur during edge rounding process but this chipping event is no longer connected to the original milling process. The measuring number can also be used for qualifying as in several cases the costumer is not only interested in the average chipping value but also in the maximal chipping depth (for example in case of tabletop or kitchen element).

\section{Experiments to define the replacement piece}

It is necessary to develop a system for the calculation of average edge chipping rate described in chapter 4.1. Based on this system we can define accurately the resulting volume loss during the milling process. Chipping volume on tested edge length becomes effectively measureable based on the examination methods discussed in chapter 5. Further aim of the examinations is to create a piece that can replace the chippings with high precision. Geometry of chippings can not be defined with mathematical formulas or just on a very complicated way therefore it is absolutely necessary to develop a replacement piece. With the use of this piece average edge chipping rate of stone products can be defined accurately with simpler measurement methods.

\subsection{Examination process}

A laser scanner (fig. 6) plays a dominant role in the examination process with the help of that the edges of milled surfaces can be digitized. Thereafter the real digital edges were created with the help of rapid prototyping software called Rapid Form from the cloud of points that includes the digitized edges. We defined the volume of edge chipping also with help of this software. After the manual evaluation the next step is to create the replacement piece.

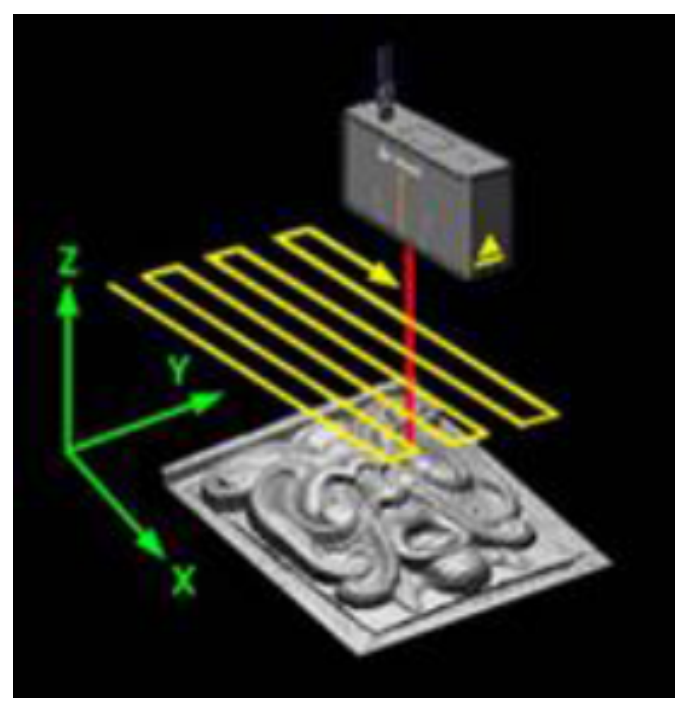

Fig. 6. Digitisation with laser scanner [12]

During the examinations we milled four sample surfaces on each of the two granite parts that have different average grain size. One of the granites was the Gallio Farfalla that has large average grain size. Gallio Farfalla is a yellowish-brown, greyish igneous rock. It has dense structure and crystalline granular texture. It is large grained, slightly directed granite. Typical component of this stone is off-white quartz and potash feldspars located in large nodes. Grain size of quartz is between 1$10 \mathrm{~mm}$. Other main rock component is the pink orthoclase that 

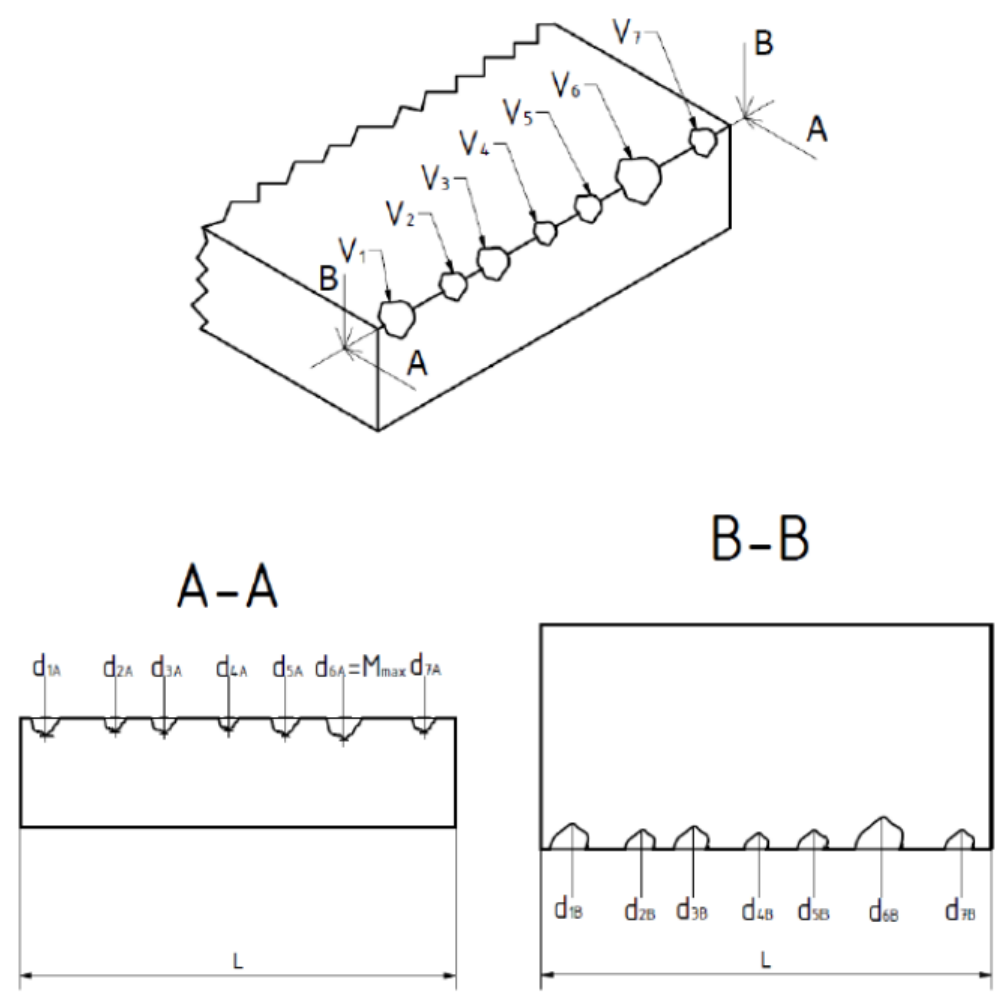

Fig. 5. Determine of the maximal edge chipping depth

has twin structure and it is board-grown. Grain size of orthoclase can reach $15 \mathrm{~mm}$. In addition to potash feldspars appear the fine-grained, board-grown plagioclases that have less than $1 \mathrm{~mm}$ grain size. There are additional colourful components in the fabric of this rock. The porosity of the rock is intergranular and less than 5 volume percent.

Another examined stone type was the medium average grain sized Rosa Beta granite. Rosa Beta is commercially available granite from Italy. It is light gray and slightly pinkish, dense structured igneous rock. It has undirected crystalline granular texture. Main rock component is quartz that is located nodular and potash feldspar. The average grain size of quartz is $1 \mathrm{~mm}$ but the size of the largest grains can reach $2 \mathrm{~mm}$. Colours of the rock is from the pink and white potash feldspars that are board grown and their grain size is over $2 \mathrm{~mm}$. Potash feldspars have twin structure that has well fissionable surfaces. Isothermal fracture surfaces of quartz are rough. There are some colourful mixture parts arranged in nodes in fabric of the rock. These parts are biolith micas and pyroxenes. Their grain size is between 0,1 and $0,3 \mathrm{~mm}$. Porosity of Rosa Beta granite is intergranular. Rosa Beta is a representative of medium grain sized granites in our research.

A Prussiani type NC controlled stone machining centre was used for the machining (fig. 11. In case of both granites a $100 \mathrm{~mm}$ diameter face milling tool from 22 parts was used for the examinations (fig. 2). On the sample surfaces the cutting speed was $188 \mathrm{~m} / \mathrm{min}, 283 \mathrm{~m} / \mathrm{min}, 377 \mathrm{~m} / \mathrm{min}$ and $1225 \mathrm{~m} / \mathrm{min}$.
Width of the sample surfaces was $45 \mathrm{~mm}$. During the machining process of sample surfaces the machining depth was $1 \mathrm{~mm}$ in all cases. Up-cutting method was used for machining.

We digitized the surfaces that are created during the machining with the help of a laser scanner called Scantech. After that we evaluated manually the chipping on each sample surfaces. The chipping which depth is less than $0,1 \mathrm{~mm}$ was not taken into consideration. Those chippings that have lower depth than $0,1 \mathrm{~mm}$ are inside the margin of error because of the precision of the laser scanner $(0,05 \mathrm{~mm}$ per axle). During the evaluation we tabulated the distance between the start and end points of chippings on each sample surfaces and the maximal measurable chipping depths on the two surface elements of the edge. We found a total of 65 chippings on the 8 sample surfaces. Number of chippings was between 6 and 10 on each sample surfaces. Fig. 7 shows one of the chippings on second sample surface of Rosa Beta granite. Negative of the same chipping can be seen on fig. 8. This negative is a volume loss that is created in the range of chipping during the machining. If the volume loss is converted to a piece the software can automatically calculate the volume of it.

\subsection{Defining the total volume reduction of the examined edges}

All of the sample surfaces of the two granite types were digitized during the examinations. In case of the 8 sample surfaces we tabulated the typical size of all the chippings on surfaces and the volume loss. Table 1 shows the typical sizes of chippings on 


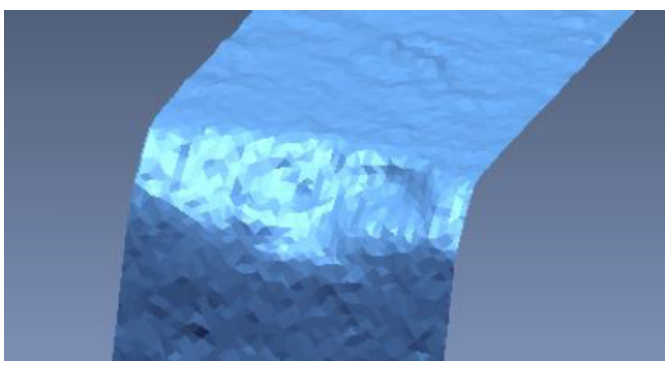

Fig. 7. Fifth edge chipping of second sample surface of Rosa Beta (R2)

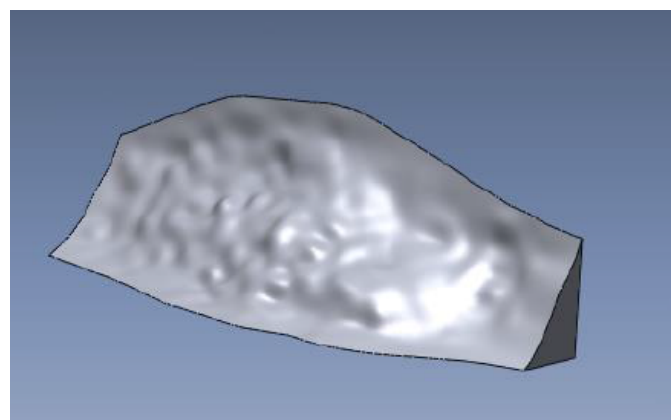

Fig. 8. Negative of edge chipping of Fig.7

sample surface of Gallio Farfalla granite that is machined with $188 \mathrm{~m} / \mathrm{min}$ cutting speed.

In the table 1 "the concrete volume" is the volume of the edge chipping calculated by the Rapid Form software. We can calculate the "volume of tapered shell" with the next formula Eq. (6):

$$
V_{t s}=\frac{1}{4} \cdot\left(\frac{1}{3} \cdot \pi \cdot a \cdot b \cdot h\right) \cdot 2=\frac{1}{6} \cdot \pi \cdot a \cdot b \cdot h
$$

Where:

- $V_{t s}$ is the "volume of tapered shell" $\left[\mathrm{mm}^{3}\right]$

- $a$ is the "radius of first short axis" [mm]

- $b$ is the "radius of second short axis" [mm]

- $h$ is the "radius of long axis" [mm]

Total volume reduction of the examined edge that is needed for average chipping depth calculation became definable with the help of the examination method that is described in chapter 5 . Error of the laser scanner $(0,05 \mathrm{~mm}$ per movement axes) and the surface fitting error of rapid prototyping software generates measurement error in the examination method. The software builds up the surface from triangles with $0,1 \mathrm{~mm}$ side length on the point cloud that is created by the laser scanner. Because of this the digitization of geometries under $0,1 \mathrm{~mm}$ is limited.

\subsection{Examination of the piece that replaces the chipping vol- ume}

Additional aim of the examinations that are described in chapter 5 is to find a characteristic piece that can accurately replace the volume losses generated by the random shaped chippings that are created during the milling process. The examinations showed that the more geometrical parameters we use in case of the chipping, the more accurate replacement piece we can get.
We looked for a more complex but mathematically easily definable replacement pieces starting from the quarter sphere that is the simplest piece. At the end of the examinations we could make a conclusion that the chipping geometry can be reached with the lowest error using two ellipses- based quarter cones that are connected by their sides (fig. 9). The complex cone piece is from two cones with the same volume. Height of the cone is half of the distance between the starting and end points of the chipping. Radius of the two axes of ellipses is the maximal chipping depth that can be measured on two surfaces of the chipping edge. The cone piece replacement works with three typical parameters but it gives more accurate results than the quarter-sphere replacement where only one parameter is needed, the starting and end points of the chipping.

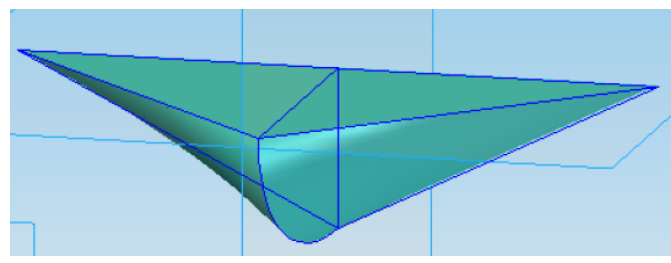

Fig. 9. The tapered shell that replaces the chipping volume

In the diagram shown on fig. 10 we compared the difference between the average volume calculated with the help of the replacement pieces and the average volume of chippings on each sample surfaces, in case of the 8 sample surfaces. We examined two cases when the chippings are replaced by quarter spheres and when we use the cone piece to the replacement.

This diagram shows that with the quarter-sphere replacement no proportionality can be found in case of the examined granites. Significant deviations can be observed in case the quarter sphere based replacement and the average volumes measured by the replacement pieces always over estimates the real average volume. This over estimation is multi-valued in most of the cases. Examination with the defined cone piece shows a clear trend compared to the average volume of the real chippings. This trend keeps the value of chipping volume -that is needed for the average edge chipping rate- inside $3 \%$ error.

We can see in table 2 that in case of the sample surfaces of the two granites the rate of volumes of the real and theoretical chippings is limited to a narrow range.

Based on table 2 we can declare that we can effectively replace the chipping geometries with the help of the cone piece that is found during the examinations because the value of error in the examined cases was under $\pm 3 \%$.

The volume of the cone piece can be put into the Eq. (1) equation. The total volume reduction of the examined edge can be written with the help of the three parameters of chippings in the 
Tab. 1. Determination of chipping volumes of first sample surface of gallio farfalla granite

\begin{tabular}{|c|c|c|c|c|c|}
\hline $\begin{array}{l}\text { No. Of edge } \\
\text { chipping }\end{array}$ & $\begin{array}{l}\text { Radius of long } \\
\text { axis [mm] }\end{array}$ & $\begin{array}{c}\text { Radius of first } \\
\text { short axis } \\
\text { [mm] }\end{array}$ & $\begin{array}{c}\text { Radius of } \\
\text { second short } \\
\text { axis [mm] }\end{array}$ & $\begin{array}{c}\text { Concrete } \\
\text { volume }\left[\mathrm{mm}^{3}\right]\end{array}$ & $\begin{array}{c}\text { Volume of } \\
\text { tapered shell } \\
{\left[\mathrm{mm}^{3}\right]}\end{array}$ \\
\hline 1 & 1,4052 & 1,0422 & 2,1522 & 1,3373 & 1,6495 \\
\hline 2 & 1,9726 & 0,9642 & 1,5690 & 2,1438 & 1,5617 \\
\hline 3 & 2,2926 & 1,4473 & 1,4423 & 3,0609 & 2,5045 \\
\hline 4 & 1,525 & 0,9701 & 1,1593 & 0,6778 & 0,8976 \\
\hline 5 & 2,0251 & 0,8419 & 2,0383 & 1,3220 & 1,8187 \\
\hline 6 & 1,0475 & 0,5644 & 0,7814 & 0,2676 & 0,2418 \\
\hline \multirow[t]{5}{*}{7} & 0,9185 & 0,7170 & 1,8652 & 0,6043 & 0,6428 \\
\hline & & & & $\begin{array}{l}\text { Average of } \\
\text { concrete } \\
\text { volumes }\end{array}$ & $\begin{array}{c}\text { Average of } \\
\text { tapered shells }\end{array}$ \\
\hline & & & & 1,3448 & 1,3309 \\
\hline & & & & & $\begin{array}{c}\text { Rate of average } \\
\text { values }\end{array}$ \\
\hline & & & & & $98,97 \%$ \\
\hline & GALLIO & FFALLA GRANIT & FIRST SAMPL & URFACE & \\
\hline
\end{tabular}

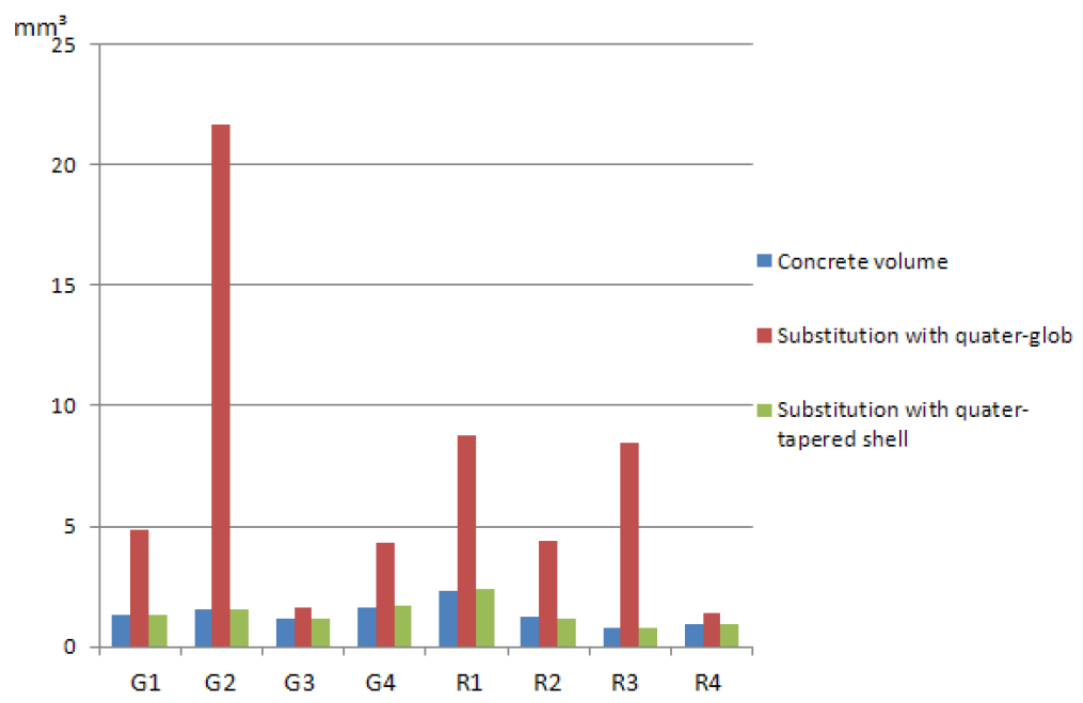

Fig. 10. Comparison of concrete and theoretical average volumes

Tab. 2. Result of investigation of substituting with quater-tapered shell

\begin{tabular}{|c|c|c|c|}
\hline $\begin{array}{c}\text { Name of the sample } \\
\text { surface }\end{array}$ & $\begin{array}{l}\text { Average volume of the } \\
\text { edge chippings }\left[\mathrm{mm}^{3}\right]\end{array}$ & $\begin{array}{l}\text { Average volume of the } \\
\text { substituting }\left[\mathrm{mm}^{3}\right]\end{array}$ & $\begin{array}{l}\text { Proportion of the } \\
\text { theoretical and the } \\
\text { concrete volumes }\end{array}$ \\
\hline Gallio Farfalla 1. (G1) & 1,3448 & 1,3309 & $98,97 \%$ \\
\hline Gallio Farfalla 2. (G2) & 1,2991 & 1,291 & $99,37 \%$ \\
\hline Gallio Farfalla 3. (G3) & 1,1768 & 1,1769 & $100,02 \%$ \\
\hline Gallio Farfalla 4. (G4) & 1,288 & 1,2572 & $97,61 \%$ \\
\hline Rosa Beta 1. (R1) & 2,3259 & 2,3829 & $102,45 \%$ \\
\hline Rosa Beta 2. (R2) & 1,2104 & 1,1845 & $97,86 \%$ \\
\hline Rosa Beta 3. (R3) & 0,7806 & 0,7703 & $98,68 \%$ \\
\hline Rosa Beta 4. (R4) & 0,8487 & 0,8444 & $99,49 \%$ \\
\hline
\end{tabular}


following way:

$$
\begin{aligned}
& \sum_{i=1}^{n} V_{i}=V_{1}+V_{2}+\ldots+V_{n}= \\
& =\frac{1}{6} \cdot a_{1} \cdot b_{1} \cdot h_{1} \cdot \pi+\frac{1}{6} \cdot a_{2} \cdot b_{2} \cdot h_{2} \cdot \pi+ \\
& +\ldots+\frac{1}{6} a_{n} \cdot b_{n} \cdot h_{n} \cdot \pi
\end{aligned}
$$

Where:

- $a$ is the maximal depth of the edge chipping on the first surface $[\mathrm{mm}]$

- $b$ is the maximal depth of the edge chipping on the second surface [mm]

- $h$ is the half of a distance between start point and endpoint of edge chipping [mm]

\section{Conclusions}

Research in this study investigates the creation of a qualification system in case of milled surface's edge of stone products. This system gives a method that can objectively define the average edge chipping rate and the maximal chipping depth of stone products made during the milling process. Paper shows that researches that can be found in international literature only marginally and indirectly deal with qualification of stone edges. Actually there is no measurement method and test system for qualification of milled stone surface's edges that significantly makes difficult the work of stone machining firms during the acceptance testing of finished products.

Study described in more details the relations including the bases of definition of the average edge chipping rate and the maximal edge chipping depth of the qualification system that developed during the research. In fifth chapter a testing system was described with that we can effectively define the volume reduction of milled edges' chipping in case of granites. Additional aim of the machining and measurement processes was to find a replacement body with that the chipping volume can be define with high accuracy in knowledge of chipping parameters. Studies have pointed out that in case of Rosa Beta and Gallo Farfalla granites, the replacement with two quarter cones that are connected by their sides form proportional within a narrow range of variation to the real chipping volume reduction by the measurement of sample surface that were produced with the examined parameters.

In the next phase of the research broad spectrum of experiments were preformed in order to confirm statistically the overall usability of the replacement. After the series of experiments we developed a simple, fast and effective measuring method and with the help of that the characteristics of milled edges chipping of stone products can be defined accurately also in knowledge of chipping parameters.

\section{Acknowledgements}

The authors would like to thank Gyula Emszt (BME Department of Construction Materials and Engineering Geology), Zsuzsanna Kun demonstrator (Department on Manufacturing Sciences and Technology) for their help in the evaluation of the experiments. We wish to thank István Gyúrós, head of the Woldem Ltd. and György Falk, owner of Varinex Ltd. for technical support in machining and scanning processes.

\section{References}

1 Kertész P, Szabó-Balog A, Provenance and petrographical problems of the building and ornamental stone materials of Hungarian renaissance architecture, Periodica Polytechnica Civil Engineering, 32, (1988), 169-194.

2 Bagi K, Bojtár I, Gálos M, A note on the role of internal structure of rocks in the deviations of compression strength results, Periodica Polytechnica Civil Engineering, 43(2), (1999), 169-178.

3 Ribeiro RP, Paragassú AB, Moreiras STF, Factors affecting slab surface roughness of siliceous dimension stones, Bulletin of Engineering Geology and the Environment, 70, (2011), 625-631, DOI 10.1007/s10064-010-03454

4 Xie J, Precision grindability of granite in relation to discrete distribution parameters of microhardness and microbrittleness, Journal of Manufacturing Science and Engineering, 132, (2010), 1-7, DOI 10.1115/1.4001578

5 Huang H, Li Y, Shen JY, Zhu H M, Xu X P, Micro-structure detection of a glossy granite surface machined by the grinding process, Journal of Materials Processing Technology, 129, (2002), 403-407, DOI 10.1016/S09240136(02)00702-1

6 Huang $\mathbf{H}, \mathbf{X u} \mathbf{X} \mathbf{P}$, Interfacial interactions between diamond disk and granite during vertical spindle grinding, Wear, 256, (2004), 623-629, DOI 10.1016/j.wear.2003.10.005

7 Polini W, Turchetta S, Force and specific energy in stone cutting by diamond mill, International Journal of Machine Tools \& Manufacture, 44, (2004), 1189-1196, DOI 10.1016/j.ijmachtools.2004.04.001

8 Gogotsi G, Mudrik S, Galenko V, Evaluation of fracture resistance of ceramics: Edge fracture tests, Journal of Ceramics International, 33, (2007), 315-320, DOI 10.1016/j.ceramint.2005.09.017

9 Mohajerani A, Spelt JK, Edge chipping of borosilicate glass by low velocity impact of spherical indenters, Journal of Mechanics and Materials, 43, (2011), 671-683, DOI 10.1016/j.mechmat.2011.06.016

10 Mohajerani A, Spelt JK, Edge chipping of borosilicate glass by blunt indentation, Journal of Mechanics and Materials, 42, (2010), 1064-1080, DOI 10.1016/j.mechmat.2010.10.002

11 Bao RH, Zhang LC, Yao QY, Lunn J, Estimating the Peak Indentation Force of the Edge Chipping of Rocks Using Single Point-Attack Pick, Rock Mechanics and Rock Engineering, 44, (2011), 339-347, DOI 10.1007/s00603-010-0133-2

12 Falk G, 3D scanning and CNC milling related to wood carving, Varinex Zrt., 2010, http://www.sasovits.hu/cnc/irodalom/3d/3D_szkenneles_ maras.pdf 